\title{
ONLINE LEARNINg DURING COVID-19 PANDEMIC, AND POSSIBILITY OF ADOPTING COMPUTER-BASED TEST
}

\author{
Rabea Emdas ${ }^{1}$ and Ahmed Alruwaili ${ }^{2}$ \\ ${ }^{1}$ Faculty of Science, Engineering and Technology, Swinburne University of Technology, \\ Hawthorn, Victoria 3122, Australia \\ ${ }^{2}$ Department of Computer Science and Information Technology, La Trobe University, \\ Bundoora, Victoria 3086, Australia
}

\begin{abstract}
COVID-19 pandemic has impacted the educational institutions in Australia and New Zealand, thus online learning was a significant option for education to be smoothly continued. This could possibly enhance the Computer-based exams (CBEs) to be used in various courses, such as schools, universities and other training centres. As there are many educational institutions which have chosen to convert from paper test system to computer- based exam. However, adopting computer tests may lead to some difficulties for the students, which relates to technical defects and lake of computer skills of some students when they are applying the computer based exams. The purpose of the paper was to discuss online learning during Covid19 and the possibility of adopting (CBEs), then to determine negative and positive effects on the students of using computer-based exams and focus on some of suggesting solutions to the negative effects. Computer test which could cause negative effects on students due to various levels of skills to use a computer and some technical problems was examined. The design of the computer examination system requires careful planning and study from several aspects before becoming officially accepted, the computer-based exams still have a few problems which may lead to difficulties in using computer exams. Then the many benefits which could be gained by using computer-based exams, such as the student will be more independent with computer test were described. In addition, the students have access to the exams through the internet network. Finally, the effectiveness of certain strategy to solve the negative effects of computer-based exams were argued. Developing the solutions of the technical problems are required for computer test, where improving the input methods questions and corrections. It was resulted that online learning has considered as a better option during COVID-19 pandemic, and the computer exam, with adjustments, is more suitable for students.
\end{abstract}

\section{KEYWORDS}

E-learning, COVID-19, online education, Computer-Based Exams, Computer test.

\section{INTRODUCTION}

Covid-19 pandemic has globally impacted on economic and social life, causing a restricted health case for many people, it resulted lockdown in many cities around the world. As a result, online learning was a better option for education at this case. Recently, there are more institutions offering online courses, either for undergraduate or higher degree level, and raise of the number of students whom study online to gain qualifications. With rapid developments of technology, online learning could be considered as a better option for effective education rather than offline learning. 
However, the research still required for more evidence [1,2]. The computer-based test is a system designed for the students to do exams via computer. Therefore, electronic devices which are providing developed software have changed to be more suitable in educational operation $[3,4]$. All these developments of the schooling devices have made it possible for students to do computer tests with better performance. On the other hand, adopting computer tests may lead to some difficulties for the student, which is related to technical defects and computer skills when applying the computer-based exam. These difficulties prevent the application of the computer test easily. For example, unequal levels of computer skills among the users could be a barrier to apply this kind of test equally. In addition, technical problems that are related to hardware and software are considered as one of the practical problems $[5,6]$. However, there are some advantages for the computer-based exam compared with the paper tests and that represented in easy access and accuracy of the assessment of the questions. As a result, the students become more independent in the study, due to the student not receiving help from anyone. This paper will discuss online learning during covid-19, as well negative and positive effects on the students when the computer-based exams been used and focus on suggesting some solutions to the negative effects of such exams to make continuous use of the computer-based exams possible [7,8].

\section{Format GUIDE}

Computer-based exams (CBEs) are software of computer that support test papers to present electronically. According to Bennett, Braswell, Oranje, Sandene, Kaplan and Yan [7], electronic tests are powered by a database containing all the subjects' data of the student. In addition, electronic tests have function which are correcting the questions accurate and showing individual results for each question. According to Goldberg and Pedulla [6], computer-based exams are supported the materials and topics differently, such as questions of mathematics test would use many functions more than history questions. The test which is done by the computer includes questions that are connected by database. Therefore, computer-based tests might have less error than the paper examinations. The computer exam is highly bases on the new technology, in order to accurately assess the performance of the students during the exam. For example, supporting of the new functions and developed versions of the software where used in the exam $[9,10]$. The electronic system test is designed to be done by computer which is provided with many options. For example, the computer test could have direct messages which can displayed as a result for each question [8]. In addition, the exam which using the computer based is more accessible for students even through the internet, while the paper examination could not support like this option $[8,11]$.

\section{Evolution Of ONLine Education in Australia AND New Zealan}

Online education was growing dramatically in Australia and the Pacific region, according to Shailendra, Prageet, Parul, Diptiranjan ,Ratri, Rebecca and Sumita [12], Swinburne University of Technology (SUT), is one of the main Australia's online learning sector, where reflecting on the national growth in the online learning experience of different of Australia's online learning providers. Moreover, Swinburne University of technology has growth in open access online learning which became as 'a national leader in online higher education' with its achieved partnership with Open University Australia (OUA), which is a collaborative project with some leading universities in Australia, where Swinburne University is a partner and contributor to it. However, lacking of Australian infrastructure has been recognized in particular high bandwidth connectivity through remote locations that was an issue which could be mitigated via providing an offline handling capability. This would call for quick synchronization setup between offline and online frameworks to confirm that the student got high quality of education. Online learning 
is an effective tool for a collaborative learning, and generally has very rich context. As a result, elearning in New Zealand would have a better future learning outcomes and better expected relationship between student and teacher. Thus, online education has been recognized in Australia and New Zeeland, to be such an effective tool for a collaborative learning that has a popular growing $[12,13]$.

\section{COVID-19 AND SOME USED TOOLS IN E-LEARNING}

The World Health Organization (WHO) was declared that the COVID-19 pandemic is a disease that caused by the 2019 novel coronavirus, which caused of millions of cases who effected around the world that had brought a dramatic change in our lives. Social distancing has led to a significant decline in the performance of education in the traditional way. Thus, the effects of the pandemic have created a strong opportunity for online education as an alternative for traditional educational practices [14,15]. Seymour-Walsh, Weber, and bell [16], stated that classroom lecture has many advantages which allows the teacher to understand more about the student, including any expressions of the student during class that enable clear and direct interpretation of the student engagement. Furthermore, having students in class and discussing a topic improves students' understanding during the lecture. In contrast, during online learning the student may face a technological barrier or may feel an isolated from their peers, even in very interactive online class that would affect the student's knowledge. Accoring to Lorenza, and Carter [17], specified that what students considered online education as successful features of educational method, easy way to get access to the materials, quickly respond to inquiries, and good quality of technology and its positive features for education. Moreover, this was a good area for students to actually managing their time, and enhances learning outcomes, as well flexible assessment online. Sodhar, Jalbani, Buller, and Sodhar [18], stated that online learning process has many available tools that used during online teaching, some of these tools are paid, which have some extra features, and some are unpaid tools. However, through some the tools the students would perform their e-learning activities, these tools commonly be used in online learning; such as: YouTube channel, WhatsApp group, Zoom meeting, Facebook group, Google class, Email, MS Office 360, and Recorded PowerPoint presentation.

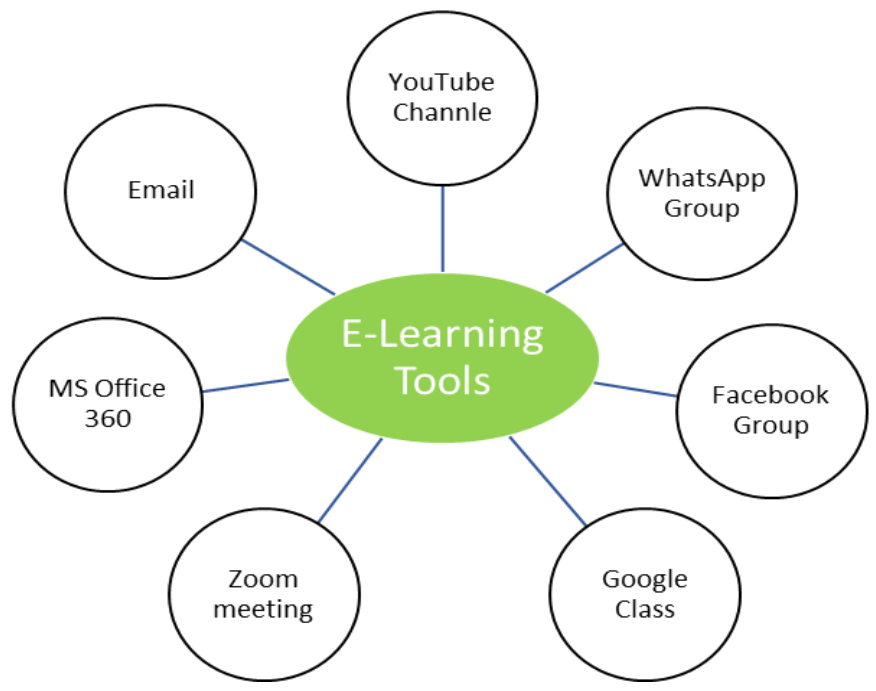

Figure 1: Shows some of the tools that used in E-learning. 


\section{The Negative IMPACTS OF THE COMPUTER TeSt ON STUdentS}

The use of computer tests may have significant negative impacts on the student when the student is doing computer exams. According to Frankel, Altschuler, George, Kinsman, Jimison, Robertson and Hsu [19], the computer-based exam has a high accuracy when calculate the errors of the students during the exams. Consequently, lack of computer skills might have a negative impact on students when doing the computer-based exams, because of the concentrating of student to answer questions and how to use the computer. However, the computer test is accreted and gives the specific time to the student for reviewing errors during the examination, while in the paper exam could not deal with time accurately same as and cheque errors. Figure 2 depicts elements of the Input- Skill for the student, focusing on accuracy and speed, as can be seen from figure 2, accuracy skills are 17 maximum points. While the speed skills are 22 maximum points. In the other hand, there are three main components to get familiar in computer; these components are computer experience, input accuracy, and input speed, where a minimal level for each component should be gained in order to effectively do a computer-exam. When the exam has a question that requires a constructed response, here is where the computer experience highly required. As well input accuracy, and input speed that should be important for the student to correctly fill the answers [7]. Therefore, the problems of computer exams could hinder the student to continuing in the exam, which may impact on the student's performance. Due to of these similar problems the concentrating of the student could really be shifted from answering questions to technical problems. Shacham [3] stated that the computer problems which are related to hardware and software could effect on the performance of student, which is possibly making the student return the exam from beginning. These two major areas of problem might be negatively affecting the level of student performance $[8,20]$.

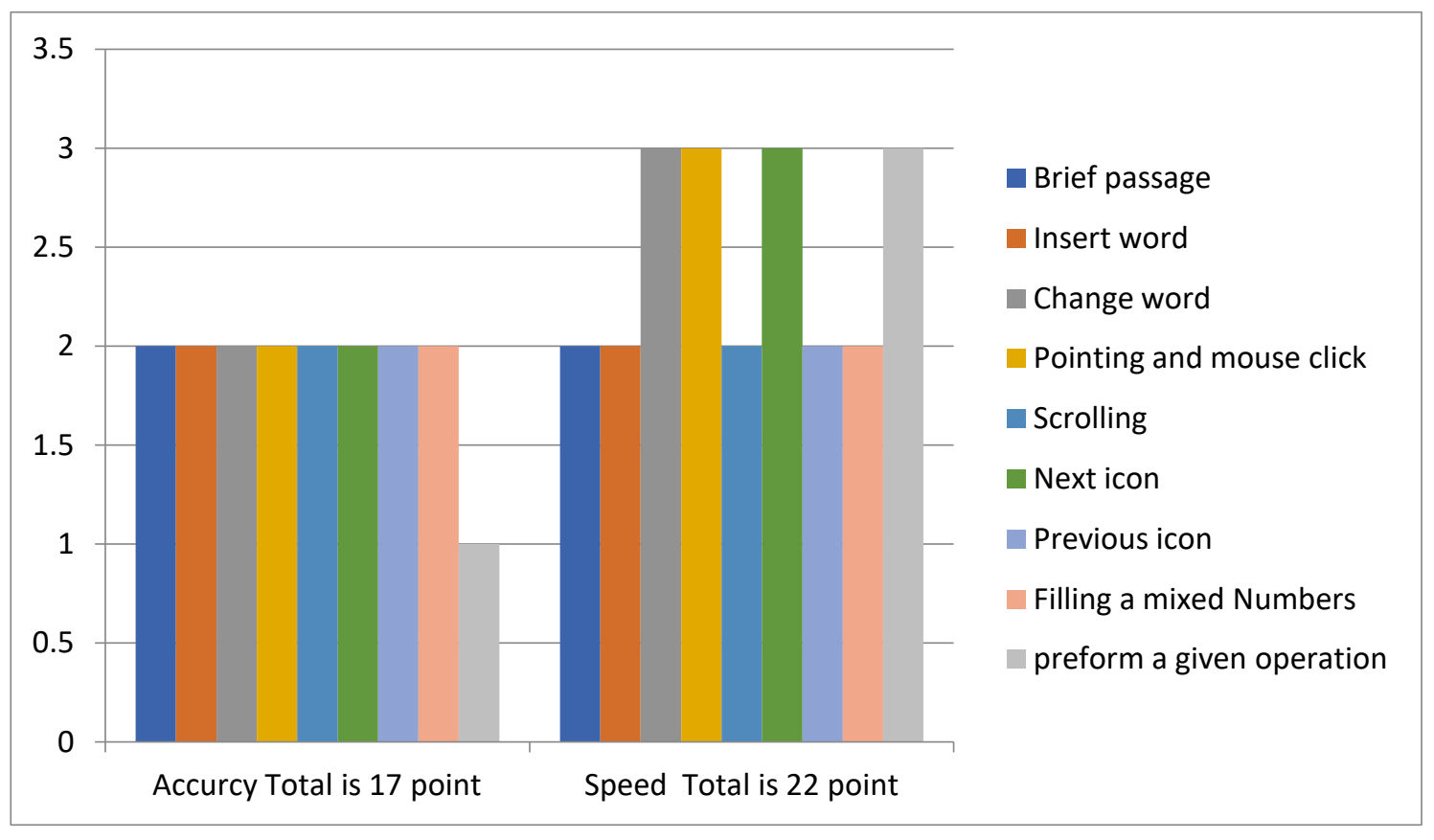

Figure 2: shows point of input accuracy and input speed components. 


\section{The Positive Effects of the Electronic Test on Students}

Using computer-based exams could have a positive effect on students, due to electronic tests provide many options for the students which were not available in the paper examinations. However, the electronic test system focuses on the time factor and quick access to records. The computer test system is provided on electronic records that are different from paper records [3, 11]. In addition, these kinds of questions could include multiple choices for the student, such as inputting maths expressions and numerical answers. Moreover, the computer-based exam calculates the time of the test accurately and displays student's mistakes at the same time. The questions show on the screen sequentially. As a result, the students could understand each question individually. Computer Based Exams (CBEs) have been used in various courses [3, 4].In such tests, all the questions are answered via individual interactive work with a personal computer. Immediate feedback on errors is provided and the rating is typically done by the computer. The time frame of the computer-based exams could be set so that the largest number of students able to redo the exam. There is no assistance to the student from anyone, which could make the student more independent. This means that the student would take responsibility for study [5]. In addition, the computer-based exam supports simulation tests for some special applications, such as computer and physics experiments. This means that the computer test can be used to simulate some practical experiments which are requiring high cost and hardware. Thus, the students can obtain a hands-on experience before commencing to do some real exam. All these steps could assist to increase the student's performance [21].

\section{The Strategies to Solve the Negative Effects of Computer - BASED EXAM}

The electronic test system may have a few errors as does any system which is built to solve a problem or develop the old system. The computer-based exam system is relatively recent compared with the paper examination system. Shacham [3] stated that the computer-based exams require extra development to support multiple functions and some tools. Therefore, the computer test should be more suitable to the students. For example, voice technology is the technique used in some international tests, such as the TOEFL exam, which gives the student a chance to display conversation skills. All these improvements in the computer system test could have a positive effect on the students whom would increase their performance. According to Mary [5] solving of technical problems can be caused to develop computer test for example, improve the input method of questions and corrections, which should make the computer exam simpler for the students. Taking into account the student's needs considering the sensitive issue of the technical problems in the computer test, which could affect skills of the students more than traditional exams. Such as the rebooting computer system for various reasons which often leads to wasting time and causes frustration. This complaint of students about computer exams is related to the technical problems, these two major strategies could solve problems of the computer test.

\section{Conclusions}

Design of the computer examination system requires a lot of planning and study from several aspects before becoming certified. Using electronic tests may have benefits to students. On the other hand, the computer-based test still has a few problems; these problems may lead to difficulties in using computer tests, such as technical problems and computer skills. As a result, the student should have sufficient time to gain good experience in using computer tests, where this test system focuses on the time factor and quick access to records, the computer- based exams calculate the time of the test accurately. Therefore, the test could assist performance of 
student, which make test more suitable for the students, such as input method questions and corrections, and using technology by various ways, where is making the computer-based exam support voice input, editing texts and easily update. However, technical problems with the hardware could be decreased by using new and well-maintained computers. It is expected that with the increase of using the computer-based exam at educational institutes, while the using of the paper examination may decrease. The main findings of the present work can be summarised as follows:

- E-learning could be considered as an optimum option during COVID-19 pandemic, especially when the end of the disease is not clearly seen yet. However, with online education could possibly adopting computer-based test with needs of more developing functions, and tools that could assist the student to gain more educational knowledge.

- E-learning been used from schools, universities, and other educational institutions.

- Computer skills are very important for the student during e-learning, missing of these skills could impact on student performance.

- E-learning in New Zealand would have a better future learning outcome.

- Online education has been recognized in Australia and New Zeeland, to be such an effective tool for a collaborative learning.

- Computer-based exam has some over positive effects compare with paper exam.

\section{ACKNOWLEDGEMENTS}

The authors would like to thank Dr Abd Alhamid R. Sarhan (Faculty of Science Engineering and Technology - Swinburne University of Technology) for his advices.

\section{REFERENCES}

[1] Peia, L., and Wub, H.: 'Does online learning work better than offline learning in undergraduate medical education? A systematic review and meta-analysis', 2019 VOL. 24, 1666538.

[2] Stone, C.: 'Online learning in Australian higher education: Opportunities, challenges and transformations'. Student Success, 2019,10, (2), pp. 1-11.

[3] Shacham, M.: 'Computer-based exams in undergraduate engineering courses', Computer Applications in Engineering Education, 1998, 6, (3), pp. 201-209.

[4] Wingenbach, G.J.: 'Agriculture Students' Skills and Electronic Exams', Journal of Agricultural Education, 2000, 41, (1), pp. 69-78.

[5] Mary, P.: 'The Effect of Using Item Parameters Calibrated from Paper Administrations in Computer Adaptive Test Administrations', The Journal of Technology, Learning and Assessment, 2007, 5, (7).

[6] Goldberg, A.L., and Pedulla, J.J.: 'Performance Differences According to Test Mode and Computer Familiarity on a Practice Graduate Record Exam', Educational and Psychological Measurement, 2016, 62, (6), pp. 1053-1067.

[7] Randy Elliot, B., James, B., Andreas, O., Brent, S., Bruce, K., and Fred, Y.: 'Does it Matter if I Take My Mathematics Test on Computer? A Second Empirical Study of Mode Effects in NAEP', The Journal of Technology, Learning and Assessment, 2008, 6, (9).

[8] Zilles C, West M, Mussulman D and Bretl T. Making testing less trying: Lessons learned from operating a Computer-Based Testing Facility. In 2018 IEEE Frontiers in Education Conference (FIE), pp. 1-9.

[9] Morrison, B.B., Margulieux, L.E., Ericson, B., and Guzdial, M.: 'Subgoals help students solve Parsons problems', in Editor: 'Book Subgoals help students solve Parsons problems' (2016,edn.), pp. 42-47.

[10] Zilles, C., Deloatch, R.T., Bailey, J., Khattar, B.B., Fagen, W., Heeren, C., Mussulman, D., and West, M.: 'Computerized testing: A vision and initial experiences', age, 2015, 26, pp.1. 
[11] Hainey, T., Connolly, T.M., Boyle, E.A., Wilson, A., and Razak, A.: 'A systematic literature review of games-based learning empirical evidence in primary education', Computers \& Education, 2016, 102, pp. 202-223.

[12] Palvia, S., Aeron, P., Gupta, P., Mahapatra, D., Parida, R., Rosner, R., and Sindhi, S.: 'Online education: Worldwide status, challenges, trends, and implications', Journal of Global Information Technology Management, 2018,21, (4), pp. 233-241.

[13] Wright, N.: 'e-Learning and implications for New Zealand schools: A literature review', Ministry of Education, 2010.

[14] Kaup, S., Jain, R., Shivalli, S., Pandey, S., and Kaup, S.: 'Sustaining academics during COVID-19 pandemic: the role of online teaching-learning', Indian Journal of Ophthalmology, 2020 Jun;68(6): 1220.

[15] Unger, S., and Meiran, W. R.: 'Student Attitudes towards Online Education during the COVID-19 Viral Outbreak of 2020: Distance Learning in a Time of Social Distance', International Journal of Technology in Education and Science, 2020,4, (4), pp. 256-66.

[16] Seymour-Walsh AE, Weber A, and Bell A.: 'Pedagogical foundations to online lectures in health professions education', Rural and Remote Health. 2020 May 29;20(2):6038-.

[17] Lorenza, L., and Carter, D.: 'Emergency online teaching during COVID-19: A case study of Australian tertiary students in teacher education and creative arts'. International Journal of Educational Research Open,2021,2, 100057.

[18] Sodhar, I. N., Jalbani, A. H., Buller, A. H., and Sodhar, A. N.: 'Tools Used In Online Teaching and Learning through Lock-Down'. 2020, (8), pp. 36-40.

[19] Frankel, R., Altschuler, A., George, S., Kinsman, J., Jimison, H., Robertson, N.R., and Hsu, J.: 'Effects of exam-room computing on clinician-patient communication: a longitudinal qualitative study', J Gen Intern Med, 2005, 20, (8), pp. 677-682.

[20] Zilles, C.B., West, M., Herman, G.L., and Bretl, T.: 'Every University Should Have a ComputerBased Testing Facility', in Editor (Ed.)^(Eds.): 'Book Every University Should Have a ComputerBased Testing Facility’ (2019, edn.), pp. 414-420.

[21] Blumenstein, M.: 'Synergies of Learning Analytics and Learning Design: A Systematic Review of Student Outcomes', Journal of Learning Analytics, 2020, 7, (3), pp. 13-32.

\section{AUTHORS}

Rabea Emdas is a researcher, Obtained master's degree in Science Network Systems., from Swinburne University of Technology (SUT), Melbourne, Australia. Interested research area in ICT, Cloud computing, Telecommunication and computer networks research.

Ahmed Alruwaili is a $\mathrm{PhD}$ candidate in Computer Science and Information Technology, my research interest cyber security, programming languages, educational game design and online echo chambers. I graduated with master's degree in information technology in 2020 - La Trobe University, Australia.
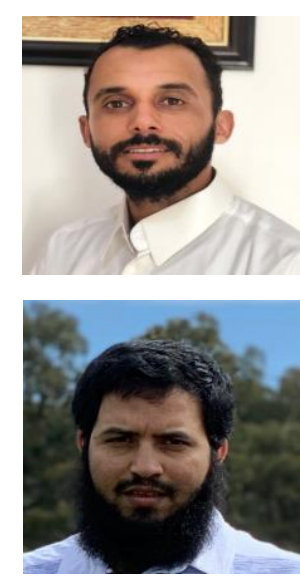